Binghamton University

The Open Repository @ Binghamton (The ORB)

$1-13-2020$

\title{
Analyses of the 2019 Nobel Prize in Physiology or Medicine: Molecular Machinery for Cellular Oxygen Level Response
}

Neyda V. Gilman

ngilman@binghamton.edu

Follow this and additional works at: https://orb.binghamton.edu/librarian_fac

Part of the Health Sciences and Medical Librarianship Commons, Other Life Sciences Commons, and the Other Medicine and Health Sciences Commons

\section{Recommended Citation}

Gilman, Neyda V. (2020). Analyses of the 2019 Nobel Prize in Physiology or Medicine: Molecular Machinery for Cellular Oxygen Level Response. Science \& Technology Libraries, 1-27. doi.org/10.1080/ $0194262 X .2019 .1703875$

This Article is brought to you for free and open access by the University Libraries at The Open Repository @ Binghamton (The ORB). It has been accepted for inclusion in Library Scholarship by an authorized administrator of The Open Repository @ Binghamton (The ORB). For more information, please contact ORB@binghamton.edu. 


\title{
Analyses of the 2019 Nobel Prize in Physiology or Medicine: Molecular Machinery for Cellular Oxygen Level Response
}

\author{
Gregg L. Semenza, William G Kaelin, Jr, and Sir Peter J. Ratcliffe were awarded \\ the 2019 Nobel Prize for Physiology or Medicine on October 7, 2019. Their work \\ led to the understanding of how cells recognize and adapt to varying oxygen levels \\ (Nobelprize.org 2019a). Hypoxia-inducible nuclear factors play an essential role \\ in this mechanism by turning on other genes that work towards increasing oxygen \\ levels in hypoxic environments. Other vital pieces of the machinery include von \\ Hippel-Lindau proteins and prolyl hydroxylation. Due to the necessity of oxygen \\ in numerous human physiological systems, this discovery will likely have nearly \\ immeasurable impacts on human health.
}

Keywords: Kaelin; Ratcliffe; Semenza; Oxygen; HIF; VHL; Nobel

\section{Introduction}

Basic and fundamental. Those two words are used over and over again to describe this year's Nobel in Physiology or Medicine. Basic is how Professor Randall Johnson, Member of the Nobel Assembly, described this year's Laureate's “discoveries of how cells sense and adapt to oxygen availability." He uses the word a few times as these discoveries relate to the very basics of how the body functions and adapts (Nobelprize.org 2019a). During his interview after the announcement, Johnson again emphasizes this point by describing the discoveries as "textbook" (Johnson 2019). While these words are often used to describe something as simple or straightforward, they are used here to emphasize the importance of these discoveries. Animal life requires oxygen and many essential cellular functions only occur at certain oxygen concentrations. Even embryos require oxygen to survive (Johnson 2019). By understanding how cells can adapt to different levels of oxygen, researchers are able to understand and possibly manipulate various diseases and negative health states.

Due to the fundamental nature of the question, a great amount of research was done in hopes of figuring out how cells change and adapt to oxygen levels and, as is often the case in science, this research initially led to confusion and conflicts (Kaelin 2002). However, the work of this year's 
three laureates ultimately came together to identify the "molecular machinery that regulates the activity of genes in response to varying levels of oxygen" (NobelPrize.org 2019b). This machinery affects many aspects of health as it allows cells to adapt to changes in oxygen needs, levels, or availability. A simple analogy for how this machinery works and affects health was proposed by Johnson during his post-announcement interview. Johnson compared the machinery to a furnace in that cells need a certain amount of oxygen to burn and they use the identified molecular machinery as a damper in order to ensure the right amount of oxygen is available. When the damper doesn't work, it is often either the result or the cause of a malfunction leading to a disease state (Johnson 2019). This is a critical system that is required for normal body function. It is also an adaptive system that allows cells to return to normal states under changes due to diseases, elevation, physical activity, age, injuries, etc. This not only increases the versatility of animal bodies but also likely played a role in animal life being able to survive in the different altitudes and environments of earth (Nobelprize.org 2019a).

\section{The science}

\section{Oxygen}

Oxygen is a gaseous element, under normal conditions, that has no color, smell, or taste. It makes up about one-fifth of the air and of all the elements it is the one that is most prevalent in the earth's crust. It is also an essential element in most living cells (Francis and Sayre 2014). Partly due to its essential nature, there have been at least three other Physiology or Medicine Nobel Prizes given to researchers studying oxygen or respiration. In 1922, Otto Fritz Meyerhof received half of the award for his work on "the consumption of oxygen and the metabolism of lactic acid in the muscle" (Nobelprize.org n.d.-a). Nine years later in 1931, Otto Heinrich Warburg Corneille won for identifying an enzyme necessary for cellular respiration (Nobelprize.org n.d.-b). Later that decade, Jean François Heymans received the 1938 award for his work looking at the regulation of respiration (Nobelprize.org n.d.-c). Now, in 2019, William G. Kaelin Jr., Sir Peter J. Ratcliffe, and Gregg L. Semenza have been awarded the prize for figuring out how cells actually recognize and adapt to changes in oxygen concentrations. 
Oxygen is necessary for almost all life as cells use it in essential processes including creating energy from food (NobelPrize.org 2019b). Fluctuating oxygen concentrations is often associated with both acute and chronic physiologic functions (Semenza 2001). Changes in cellular oxygen availability can be caused by aging, changes in physical activity, elevation changes, wounds, etc. Examples of how organisms adapt to lower levels of oxygen than is required (hypoxia) include increasing red blood cell production (erythropoiesis) or creating new blood vessels (neovascularization) to increase oxygen, or using glycolysis to create a metabolic pathway that does not need oxygen (Wang et al. 1995). If the cell does not adapt to the change in oxygen it can be negatively impacted, negatively impacting the entire organism. For a review on the role and a scientific history of oxygen, see Bunn, 1996.

\section{The switch}

The hormone erythropoietin (EPO) is, at least in mammals, the primary regulator of erythropoiesis (Semenza et al. 1991). It has been scientifically known as an idea since at least 1906, by name since 1948, and was purified in 1977 (Jelkmann 2007; Brown 2016). Even though it has been studied since at least the early twentieth century, how it works did not really began to be understood until the end of that century. In a 1991 article, Semenza explores the induction of EPO gene expression by a single mechanism which is activated in both hypoxia and anemia. Looking at the liver and the kidney, Semenza and his lab identified a protein complex termed hypoxia-inducible nuclear factor (HIF) that is caused by a 256 base pair shift on the 3 prime end of the EPO DNA strand (Semenza et al. 1991; Semenza and Wang 1992). This protein complex is made up of an alpha (HIF-1 $\alpha$, HIF-2 $\alpha$, and HIF-3 $\alpha$ ) and a beta (HIF-1 $\beta$ ) subunit (Kaelin 2002). In low oxygen

environments, HIF binds to the DNA segments next to EPO, regulating the hormone (press release). Semenza's lab continued working on HIF, confirming that the DNA-binding activity of Hypoxia-inducible factor 1 (HIF-1) is regulated by mechanisms both during transcription and after transcription, and that it is necessary in order for EPO transcription to encode the growth factor that regulates erythropoiesis (Wang et al. 1995). This research produced and provided complementary DNA (cDNA) and antisera (serum that contains specific antibodies) that was used for further analysis into the oxygen related regulation of HIF-1. 
HIF-1 $\beta$ is also called Aryl Hydrocarbon Nuclear Translocator (ARNT), which is one of the proteins that led to the discovery of the PAS domain, an evolutionary conserved protein family that plays a significant role in signal detection (Wang et al. 1995; L.E. Huang et al. 1998; Hefti et al. 2004). PAS is the same domain that is used in the 'circadian clock' mechanism which was awarded the 2017 Nobel in Physiology or Medicine (Gilman 2018). The critical and singular role of the HIF $\alpha$ subunits is their reaction to oxygen (L.E. Huang et al. 1998). In the presence of oxygen, the $\alpha$ subunits quickly degrade, causing the entire HIF structure to deteriorate (Kaelin 2002). Thus, HIF is only stable and active in hypoxic conditions. This idea, that HIF-1 would not be activated without the stabilization of HIF-1 $\alpha$ by a hypoxic environment, was first suggested in 1996 and by 1998 the specific oxygen-dependent domain of HIF-1 $\alpha$ was identified (L.E. Huang et al. 1996; L.E. Huang et al. 1998). This area was designated the oxygen-dependent degradation domain (ODD) and was shown to control the HIF-1 $\alpha$ degradation by the ubiquitin-proteasome pathway. Ubiquitin is a small peptide that tags proteins for degradation by proteasomes and was shown to not bind to HIF-1 $\alpha$ in hypoxic states (NobelPrize.org 2019b). By the time this discovery was made, ubiquitin-proteasome mediated degradation was already shown to be necessary to regulate a variety of transcription factors (L.E. Huang et al. 1998).

Around the same time that Semenza was identifying and exploring HIF, Kaelin was studying von Hippel-Lindau disease and certain cancers, such as renal carcinoma and hemangioblastomas of the central nervous system, that have high-vascular tumors. Kaelin's lab showed that not only is a functioning Hippel-Lindau gene (VHL) necessary to prevent the onset of cancers associated with von Hippel-Lindau disease, the gene and its protein (pVHL) are also somehow involved in cellular hypoxia response (press release). Tumors associated with von Hippel-Lindau disease were studied and found to have inactivated pVHL. They also produced EPO, which is normally produced in kidney cells, and resulted in an abundance of angiogenic peptides including vascular endothelial growth factor or vascular permeability factor (VEGF/VPF). (EPO leads to erythrocytosis, an increased number of red blood cells, while the angiogenic peptides cause new blood vessels to grow.) Their research explored functioning and non-functioning VHL, documenting that a lack of active pVHL leads to an increase in VEGF/VPF. Under normoxic conditions, a normally functioning VHL gene produced pVHL, which inhibited VEGF mRNA, thus limiting the production of the angiogenic peptides. However, hypoxic conditions somehow resulted in VEGF 
mRNA not being inhibited, allowing the peptides to be produced and create new blood vessels to increase oxygen. A defective VHL gene led to a loss of pVHL function in normoxic conditions which not only allowed VEGF to be produced but also led to the angiogenic peptides having and a 3-10 fold increase in half-life. Kaelin outline this pathway and showed that certain cancers exploit it by causing a germline mutation of the VHL gene which causes pVHL to not be produced, in turn allowing VEGF to be produced and be active longer under normoxic conditions, resulting in the tumors creating extra blood vessels for rapid growth (Iliopoulos et al. 1996).

Research into von Hippel-Lindau disease tumors, pVHL, and oxygen concentration was being done by Ratcliffe at the same time it was being done by Kaelin. Ratcliffe's lab found that pVHL and HIF form a complex that results in the destruction of HIF. In VHL defective cells, there was no pVHL and HIF $\alpha$-subunits remained stable allowing HIF-1 to remain active regardless of oxygen levels. When pVHL was re-introduced to defective VHL cells, HIF-1 returned to its normal state of only being active in hypoxic environments. Ratcliffe also showed that iron played a role in the interaction between HIF-1 and pVHL, as well as the breakdown of the HIF $\alpha$-subunits in normoxic conditions (Maxwell et al. 1999). This turned out to be the answer to why pVHL does not inhibit VEGF in hypoxic conditions as it is HIF that does the actual regulating of VEGF. Ratcliffe's research was done by looking at eleven different genes that are affected by VHL deficient renal carcinoma cells lines. Under normal conditions (functioning VHL), hypoxia led to nine of these genes being induced and two of them being repressed. Neither of these reactions were seen in the VHL deficient cells. When wild-type VHL genes were re-introduced to the VHL deficient cells, the hypoxia related responses returned. Seven of the genes explored (VEGF, GLUT-1, AK-3, ALD-A, PGK-1, PFK-L and LDH-A) were found to have hypoxia-response elements (HREs). These HREs either bound HIF-1, or were altered when no HIF-1 was available. This work showed that many cancers are affiliated with HIF-1 targets, enhancing glucose metabolism and angiogenesis to support tumor growth (Maxwell et al. 1999). These findings augment Kaelin's work by showing that a defect in VHL affects multiple oxygen-related genes, including but not limited to EPO and VEGF, often resulting in an increase in hypoxia-inducible mRNAs in non-hypoxic conditions (L.E. Huang et al. 1998). The focus of both Ratcliffe's and Kaelin's work is the relationship between pVHL and HIF, which has led to an increased understanding of how cells sense and adapt to changing oxygen levels. 
Ratcliffe developed an in vitro HIF-1 $\alpha$ ubiquitylation assay to further explore the hypothesis that pVHL is necessary for ubiquitin to recognize and degrade HIF- $\alpha$. The results confirmed the relationship, suggesting that HIF-1 $\alpha$ went through phosphorylation as part of the process, and also confirming that the HIF- $1 \beta$ subunit is not affected by ubiquitin while $\alpha$ always was, even having small amounts of ubiquitylation in VHL defective cells. VHL mutations that might affect binding with HIF- $\alpha$ were also identified discoveries that not only furthered understanding of VHL disease but also suggested that most of the pVHL molecule is utilized in the interaction with HIF (Cockman et al. 2000). Around the same time, Kaelin's lab was tying this research from Ratcliffe's lab in with the previous work of Semenza and others by showing that pVHL binds to the ODD region of HIF- $1 \alpha$ and is part of what binds ubiquitin to proteins for degradation. This connected the various pieces of the machinery, showing that a mutated VHL leads to a loss of pVHL, which in turn leads to an inability to degrade HIF in normoxic conditions leading to an overproduction of HIF target genes, including EPO (Ivan et al. 2001).

Other studies looked at pVHL and some focused on the protein's ability to move between the nucleus and the cytoplasm. HIF $\alpha$ subunits are degraded in the cytoplasm, making it essential for pVHL to be able to move to the cytoplasm in order to control HIF mediated genes (Lee et al. 1999; Groulx, Bonicalzi, and Lee 2000). This research combined with further research by Kaelin's lab showed that pVHL's ability to move between the nucleus and cytoplasm is vital for cells ability to react to oxygen levels (Ivan and Kaelin 2001).

Ratcliffe's and Kaelin's labs were two of the leading labs looking at VHL and they more than once had simultaneous findings, something that is not uncommon for researchers who share a Nobel. After both labs discovered the relationship between VHL and HIF, they both also discovered that hydroxylation of HIF, not phosphorylation as previously thought, was required for the pVHL-HIF$1 \alpha$ interaction. In hypoxic states, there is no oxygen for hydroxylation, meaning pVHL cannot bind to HIF- $1 \alpha$ and thus ubiquitin cannot recognize and degrade HIF-1 $\alpha$. Both labs also showed that this hydroxylation requires an enzyme and since hydroxylating enzymes are iron dependent, iron chelation also prevents hydroxylation and thus pVHL binding (Ivan et al. 2001; Jaakkola et al. 2001). Their articles describing their respective work were both published in the same issue of 
Science, one right after the other. In these experiments, Ratcliffe's lab identified the specific area of HIF- $1 \alpha$ required for pVHL interaction as HIF- $1 \alpha$ residues 556 to 574 and identified the enzyme as a prolyl-4-hydroxylase. Thus, the enzyme was termed HIF- $\alpha$ prolyl-hydroxylase (HIF-PH) and the area of HIF identified as the hydroxylation point is proline residue HIF-1 $\alpha$ P564 (Jaakkola et al. 2001). This work by Ratcliffe and Kaelin identified HIF-PH as the oxygen sensing part of the molecular machinery that allows cells to adapt to oxygen levels. As with most science, the work also lead to additional questions including if prolines in other molecules are sites for hydroxylation and the possibility that understanding HIF-PH may lead to future identification of pVHL tumor suppressor substrates (Jaakkola et al. 2001).

\section{Summing it all up}

Cells can sense oxygen levels and adapt accordingly, primarily through HIFs, hypoxia-inducible nuclear factors. HIFs are proteins that degrade quickly in conditions with normal oxygen levels but are stable in hypoxic conditions. When HIFs are stable they regulate certain genes that in turn increase oxygen levels, or affect glucose management, in various ways (Wang et al. 1995). These genes include erythropoietin that increases red blood cell production, as well as vascular endothelial growth factor and platelet-derived growth factor B chain that create new blood vessels (Hoffman et al. 2001). In conditions with oxygen, the oxygen hydroxylases a certain part of HIF (HIF-1 $\alpha$ ) which makes it so that the protein pVHL can bind to it. This binding of pVHL to HIF$1 \alpha$ marks the compound for destruction by the ubiquitin-proteasome pathway. When HIF- $1 \alpha$ is destroyed, the entire HIF protein becomes unstable and thus the oxygen-increasing genes are never activated. In conditions with no oxygen, hydroxylation of HIF-1 $\alpha$ cannot occur so HIF remains stable and activates the genes that result in increased oxygen. This mechanism was found in all tissues, marking it as a general, and essential, molecular pathway that cells of many different types use to get the oxygen they need (press release). It has been shown to be evolutionarily conserved from about 500 million years ago, having been identified in both C. elegans (nematode) and Drosophila (fruit fly) (Epstein et al. 2001; Kaelin 2002; Peter J. Ratcliffe 2016). 


\section{Significance and current/future science}

Oxygen is necessary for vital mammal metabolic processes, including the process that leads to the formation of Adenosine triphosphate (ATP), a molecule that is the "root of all organisms energetics" (Wang et al. 1995; Cole 2016). In order to ensure cells get the oxygen they need for all the essential processes that rely on oxygen, animal bodies have sophisticated and complicated systems that make use of hypoxia-response elements (HREs). There are at least 300 HREs that affect all aspects of physiology including metabolism, exercise, embryonic development, immune response, altitude adaptation, and respiration. HREs also affect the pathophysiology of anemia, cancer, stroke, infection, wound healing, myocardial infarctions, and fetal development (Nobelprize.org 2019a). There has also been research looking at ischemic and neoplastic diseases affected by angiogenesis, and even how diabetes can lead to decreased blood flow to the eye, eventually leading to blindness, a process in which VEGF has been shown to have a roll (Semenza 2000). In his 2000 review, Semenza discusses the wide range of research, including nonphysiological focused research, that contributes to the understanding and acknowledgement of the critical role oxygen homeostasis has on human development, physiology, and disease.

The most common causes of US mortality include ischemic cardiovascular diseases, cancers, strokes, and chronic lung diseases, all of which are affected by hypoxia and could be potential areas where HIF-1 manipulation can be utilized in treatment (Semenza 2001; National Center for Health Statistics 2017). These diseases and effects are just some of the examples of the wideranging impacts cellular adaptation to oxygen levels can have and why the discoveries leading to this year's award are critical. In addition to the manipulating oxygen, HIF also controls iron metabolism, adding to its vital role (Nobelprize.org 2019a).

A search in Web of Science shows that there has been a great deal of research published looking at how HIF can be manipulated or targeted for treatments of diseases. In just the last few months of 2019, research has been published looking at, but not limited to, cancer, strokes, anemia, diabetes, dental surgery, and organ injury due to alcoholism. Inflammation has also been studied in various areas including chronic kidney disease and sepsis (Fitzpatrick 2019; H. Huang et al. 2019). Chronic kidney disease has been one of the main areas of research as the kidney is where EPO is normally produced and a decreased amount of EPO due to renal failure often leads to 
anemia (NobelPrize.org 2019b). This is also the area of one of the first pharmaceutical therapies, as China has recently approved a drug that increases HIF expression to treat anemia due to chronic kidney disease (Chen et al. 2019; Nobelprize.org 2019a).

Cancer is another of the primary focus areas for potential HIF treatments due to a cancer gene (VHL) being an essential piece of the HIF hypoxia regulation machinery, as well as the diseases being so widespread and impactful. It is known that cancer takes advantage of this machinery to grow tumors quickly (Nobelprize.org 2019a). Ratcliffe's work showing that the downregulation of HIF is all that is needed for at least renal carcinomas to be suppressed by pVHL has itself led to clinical trials for future HIF inhibition treatments. His lab is also looking at other genes that regulate HIF similarly to VHL in order to broaden the potential therapeutic opportunities for cancers, and other diseases (Dana-Farber Cancer Institute). There is still more research needed, but recent studies have shown strong evidence that manipulating HIF, either on its own or combined with other therapies, can likely lead to the development of treatments (Albadari, Deng, and Li 2019; Chi et al. 2019; Fallah and Rini 2019; Hong et al. 2019; Laviv et al. 2019; Xu et al. 2019). Hong et al. (2019) is one of the studies looking at cancer treatments, exploring how traditional Chinese herbal medicines for cancers and strokes make use of the HIF pathway to affect angiogenesis.

Another major area of research is diabetes. Lin et al. (2019) looked at increasing angiogenesis to decrease inflammation and promote healing of diabetic foot ulcers by up-regulating the HIF-1 $\alpha$ VEGF pathway. Bessho et al. (2019) looked at how targeting HIF-1 $\alpha$ could protect kidneys from diabetic harm. Recently, during the 55th Annual Meeting of the European Association for the Study of Diabetes (EASD) in Barcelona, Spain, researchers presented a poster on their work that showed how the gene expression of both HIF-1 $\alpha$ and clock genes (a previous Nobel awarded topic) are changed by type 2 diabetes mellitus, and how this relationship could lead to future treatments of the disease (Lopez-Cano et al. 2019).

There have been many other studies investigating the manipulation of HIF for the treatment of a wide range of diseases and conditions. Yu et al. (2019) looked at HIF in regards to dental treatments and found that the possibility of HIF-1 $\alpha$ affecting bone mesenchymal stem cells could 
lead to new treatments during jaw reconstruction. Other recent research looked at how HIF reacts to alcohol consumption and its potential therapeutic role in preventing alcohol related organ injury (Morris and Yeligar 2018). There has even been research as to how HIFs can be used in tissue engineering (Esser, Roshanbinfar, and Engel 2019).

These are just a few of the studies done in the last year. There were many more studies done in the past couple decades including those that suggested pharmaceuticals could be used to block HIF hydroxylation, allowing cells a better chance of surviving diseases that result in tissue hypoxia (Kaelin 2002). In a review Semenza (2000) discusses the possibility of manipulating the HIF machinery for pregnancy and fetal conditions including preeclampsia and intrauterine growth retardation, both of which a quick search in Web of Science shows to still be heavy areas of research. There will almost certainly be many more studies looking at a wide range of conditions in the coming years. The fundamental, basic, essentialness of oxygen for life makes the impacts of the discovery of this molecular pathway, and the potential treatments using it, far-reaching and seemingly limitless.

\section{The scientists}

Despite having never worked directly together, this year's three laureates worked off each other's work, have a lot in common, and are happy to share the award with each other (Nobelprize.org 2019a). All three are physician scientists, which is something both Kaelin and Semenza brought up as being significant in their nobelprize.org interviews. Semenza explained the importance as "having people who are kind of there at the boundary between research and medicine to facilitate the discovery of knowledge that will translate ultimately to improvements in clinical practice" (Semenza 2019).

All three started by studying fairly focused, narrow topics but their work ended up coming together and uncovering something that is fundamental to life on earth and may have incredibly wide ranging impacts on countless diseases and conditions. The unknown of science is another topic that came up in all three of their interviews as well as their speeches when awarded the 2016 Lasker award. They all see science as a puzzle to figure out and that it should be done for the sense of discovery, not with a particular application in mind. Kaelin has said, "The most dangerous result 
in science is the one you were hoping for, because you declare victory and get lazy" (Ledford and Callaway 2019). During Kaelin's Lasker speech, he emphasized that scientists should be able to follow their curiosity to learn, explore, and not be required to work with a specific goal in mind as with engineering (Kaelin 2016). During their speeches, Ratcliffe talked about doing the work due to it being interesting and surprising, and Semenza said that serendipity is one of the great things about science (Peter J. Ratcliffe 2016; Semenza 2016). In a recent Nature News article, all three were said to be humble and great role models for other scientists (Ledford and Callaway 2019).

The three laureates also share some prestigious awards. These include the 2010 Canada Gairdner International Award, 2012 Grand Prix scientifique de la Fondation Lefoulon-Delalande, 2014 Wiley Prize in Biomedical Sciences, the 2016 Albert and Mary Lasker Foundation Lasker Award for Basic Medical Research, which is sometimes seen as a precursor to the Nobel award, and the 2018 Massry Prize (Dana-Farber Cancer Institute ; Keck School of Medicine ; Wiley 2014; Kaelin 2019).

The bibliometrics section for all three laureates was completed using data from Clarivate Analytics' Web of Science (WoS). A search for each laureate was done on November 15, 2019 using WoS's new beta Author Search. This new author search works differently than the previous WoS author search and the data provided changes depending on the detail needed. A quick overview is provided that takes into account everything in the WoS Core Collection. However, when looking for more detailed information the data only takes into account the information that the subscription being used has access to. The WoS subscription used for this analysis does not currently have access to all of the back files and thus there are some discrepancies in citation counts that can affect H-index calculations. Both sets of numbers are provided in the bibliometrics section for each laureate.

\section{William G. Kaelin, Jr}

\section{Life, education, and career}

William G. Kaelin Jr. was born in 1957 to William G. and Nancy Kaelin in New York, New York

(Nobelprize.org 2019a; "William G. Kaelin" 2011). During high school, Kaelin attended a 
National Science Foundation summer program for mathematically gifted students that he says changed his life, partly because it showed him he enjoyed being challenged and being around people smarter than himself that he could learn from (Kaelin 2016). After high school, he attended Duke University, where a research project led him to believe clinical science wasn't in his future and thus he focused on becoming a physician, earning undergraduate degrees in Mathematics and Chemistry in 1979 and then his M.D. from Duke University School of Medicine in 1982 (Vanderbilt University Medical Center Office of Research ; Kaelin 2016). He trained in internal medicine at John Hopkins University where he was a house office and chief resident in internal medicine (Lilly). He was also a medical oncology fellow and postdoctoral fellow at the DanaFarber Cancer Institute. During this time, he was in Dr. David Livingston's laboratory as a James S. McDonnell Scholar and began studying tumor suppressor proteins (Lilly ; Vanderbilt University Medical Center Office of Research). It was Dr. Livingston who showed him he actually was good at laboratory science and he became an independent investigator with his own research lab at DanaFarber in 1992 (Lilly; Kaelin 2016). Six years later in 1998 he became a Howard Hughes Medical Institute Investigator and was a full professor at Harvard Medical School by 2002 (Nobelprize.org 2019a). He is currently a Professor in the Department of Medicine at Dana-Farber Cancer Institute and Brigham and Women's Hospital, Senior Physician at Brigham and Women's Hospital, Associate Director for Basic Research at the Dana-Farber/Harvard Cancer Center, and the Sidney Farber Professor of Medicine at the Harvard Medical School (American Association for Cancer Research ; Lilly).

During his interview with Adam Smith from nobelprize.org, Kaelin talked a lot about his thoughts on science. He is, as are Ratcliffe and Semenza, a physician-scientist and he sees this as a strength as it allowed him to immediately understand how important the regulation of oxygen is to so many human diseases, and to see the possibly pharmacological opportunities for a variety of diseases. He also discussed his belief in curiosity and hypothesis driven science, mentioning that he is drawn to science because of the "interesting puzzles" (Kaelin 2019). Kaelin's research focuses on the functions of tumor suppressor genes and proteins with the long-term goal of leading to using these proteins to develop anticancer treatments. The primary proteins his lab is focusing on are pVHL, the retinoblastoma tumor suppressor protein $(\mathrm{pRB})$, and the p53-like protein p73 (Dana-Farber Cancer Institute). 
In every interview or speech researched for this article, Kaelin makes sure to emphasize how important science for science is. He consistently states that science with a desired outcome or specific deadline is not how science should be done as it hampers creativity, serendipity, and discovery (Brown 2016; Kaelin 2016; Ledford and Callaway 2019; Kaelin 2019). In 2017, he wrote an essay in Nature where he notes that the research that won him the Lasker award (and now the Nobel) would not be considered publishable by today's standards due to the lack of grand claims. He even noted that his 2001 Science article, which, as of November 14, 2009, has been cited over 3,000 times, would have been rejected if not due to one experienced editor who stopped the rejection. His point is that science is about finding truth not the immediate impact one article makes, and he urges his fellow scientists that "the main question when reviewing a paper should be whether its conclusions are likely to be correct, not whether it would be important if it were true. Real advances are built with bricks, not straw" (Kaelin 2017; Ledford and Callaway 2019).

Kaelin has a long history of awards and accolades. He is a member of Phi Beta Kappa (1978), Alpha Omega Alpha Medical Honor Society (1983), Johns Hopkins Society of Scholars (2003), Institute of Medicine (2007), National Academy of Sciences (2010), and the American Association for Cancer Research (AACR) Academy (2014). He is also a member of the American Society of Clinical Investigation (ASCI) and the American College of Physicians, served on the National Cancer Institute Board of Scientific Advisors, the American Association for Cancer Research (AACR) Board of Trustees and the Institute of Medicine National Cancer Policy Board, and is on the Eli Lilly and Company board of directors (Dana-Farber Cancer Institute ; Lilly). In addition to the awards shared with Ratcliffe and Semenza, Kaelin's awards include: the National Institute of Health (NIH) Physician-Scientist Award and National Research Service Award (both 1990), James S. McDonnell Scholar Award (1993), Memorial Sloan Kettering Cancer Center Paul Marks Prize (2001), AACR Richard and Hinda Rosenthal Foundation Award (2006), Doris Duke Distinguished Clinical Investigator Award (2006), Duke University School of Medicine Distinguished Alumni Award (2007), Association for International Cancer Research Colin Thomson Medal (2008), National Cancer Institute Alfred Knudson Award in Cancer Genetics (2011), American Society of Clinical Investigation (ASCI) Stanley J. Korsmeyer Award (2012), Wiley Prize in Biomedical Sciences (2014), Steven C. Beering Award (2014), AACR Princess Takamatsu Award (2016), and 
the American Society of Clinical Oncology Science of Oncology Award (2016) (Dana-Farber Cancer Institute).

While swimming at a pool across the street from Johns Hopkins University School of Medicine, Kaelin met Carolyn Mary Scerbo who became his wife in 1988. The couple had two children, Katryn Grace and William (Tripp), both of whom have graduated from Yale (Marquard 2015). Carolyn, a gifted breast cancer surgeon, died in 2015 from a glioblastoma at the age of 54 (Grady 2015).

\section{Bibliometrics}

According to a WoS beta Author Search, William G. Kaelin Jr. has 284 publications, an H-index of 109 , and has been cited 44,579 times in 26,982 unique articles. The detailed data is drawn off 280 publications, resulting in an $\mathrm{H}$-index of 108. These 280 publications have been cited 43,350 times (41,961 without self-citations) from 26,945 unique articles (26,726 without self-citations), averaging almost 155 citations per publication.

The WoS data goes back to 1983, and Kaelin has been publishing that entire period. There were a few years in the late eighties where he did not have any publications, but he has published at least one article every other year between 1980 and 2020 (there are some pre-publications already out in November of 2019). His most prolific year was 1999 during which he had twenty-one articles published. This makes sense as the late 1990's and early 2000's were the period where the basic and fundamental discoveries were initially being made. Between 1996 and 2019, there were fifteen separate years where Kaelin had ten or more publications. Looking at the dates in this period where there were fewer than ten publications, one notices that these are the years that correspond with his wife's breast cancer (2003-2005) and fatal glioblastoma (2010 - 2015) (Grady 2015; Marquard 2015). (See Figure 1.)

Figure 1. William G. Kaelin, number of published items in each year. Data source: Web of Science. Retrieved 15 November 2019. 
Kaelin's publications have been cited almost as soon as he began publishing them. He has been cited at least three times a year since 1984. Those numbers quickly expand with ten citations in 1989, fifty-two in 1991, over a thousand a year by 1999, and over 2,300 times in both 2016 and 2017. (See Figure 2.) It is worth noting that one of the Kaelin's five most highly cited articles is "Comprehensive molecular characterization of clear cell renal cell carcinoma," an article authored by The Cancer Genome Atlas Research Network, which results in the article having 346 individual authors. If this article is not considered, three out of five of his most highly cited articles are about HIF, one is about cancer therapy, and one is on retinoblastoma (eye cancer). (See Table 1.) "HIF alpha targeted for VHL-mediated destruction by proline hydroxylation: Implications for O-2 sensing" published in Science in 2001 is his most cited article, being cited 3,112 times, averaging almost 164 citations a year since it was published. The journals that Kaelin publishes in are wellrespected journals including Science, Nature, Molecular and Cellular Biology, and Proceedings of the National Academy of Sciences. These latter two are his most published in, having published 20 articles in each. (See Table 2.)

Figure 2. William G. Kaelin, number of times cited in each year. Data source: Web of Science. Retrieved 15 November 2019.

Table 1. Top five most highly cited papers by William G. Kaelin. Data source: Web of Science. Retrieved 15 November 2019.

Table 2. Top five journals published in by William G. Kaelin. Data source: Web of Science. Retrieved 15 November 2019.

\section{Sir Peter J. Ratcliffe}

\section{Life, education, and career}

Sir Peter John Ratcliffe was born on May 14, 1954 in Lancashire, United Kingdom to William and Alice Margaret Ratcliffe (University of Oxford 2019; "Ratcliffe, Sir Peter (John)" 2018). He won 
a scholarship to attend Gonville and Caius College at Cambridge University where he studied medicine after a Lancaster Royal Grammar School headmaster suggest he study medicine rather than his initial interest of chemistry (Magdalen College ; Peter J. Ratcliffe 2016). He earned his Bachelor of Medicine, Bachelor of Surgery with distinction in 1978 and he began his clinical training in London at St. Bartholomew's Hospital. Later, he went on to Oxford to do specialist training in nephrology, working on the physiology of renal oxygenation and renal injury, earning his MD from the University of Cambridge in 1987 (Magdalen College ; The Canada Gairdner Foundation; The Francis Crick Institute).

While studying renal circulation physiology, he became curious about the regulation of erythropoietin and in 1989/1990 he earned a Wellcome Trust Senior Fellow in Clinical Science which allowed him to create a new laboratory, the Hypoxia Biology laboratory, at the University of Oxford's MRC Weatherall Institute of Molecular Medicine that focused on renal cellular oxygen sensing pathways. He became a University lecturer in 1992, a full Professor of Nephrology in 1996, and the Nuffield Professor of Medicine in 2003, serving as Head of the Nuffield Department of Clinical Medicine from 2004-2016 (The Canada Gairdner Foundation ; University of Oxford 2019). After his Nuffield position, he became the Director of Clinical Research at Francis Crick Institute in London in 2016. He also continues on at Oxford as the Director for Target Discovery Institute, within the Nuffield department of medicine, and as a Member of the Ludwig Institute for Cancer Research (The Francis Crick Institute). He is also a practicing clinician at the John Radcliffe Hospital in Oxford and a Magdalen College Fellow (University of Oxford 2019).

Similarly to Kaelin, Ratcliffe believes that science is about the search for answers, even when the answers don't seem to have a broad impact. During his interview with nobelprize.org's Adam Smith, Ratcliffe stated that "it is important that scientists have the courage and are allowed to derive knowledge for its own sake, i.e. independent of the perceived value at the point of creation" as you never know what the true value of a piece of knowledge will end up being and science should be done for the sake of finding knowledge (Peter J. Ratcliffe 2019). His research looks at cell oxygen sensing and signaling, and is currently focused on HIF hydroxylases, as well as related hydroxylation catalyzing enzymes, in order to understand the "biological roles of signaling through protein hydroxylation and related oxidations" and better understand how these pathways affect 
human diseases (P. J. Ratcliffe ; The Francis Crick Institute). His laboratory collaborates with others to examine various aspects, including mechanisms and functions, of non-haem HIF catalyzers. These collaborations look at a wide range of facets including "protein science, structural biology and enzymology, through cell biology, systems physiology, epigenetics and cancer biology, to translational programmes in ischaemia therapeutics and integrative human physiology" (P. J. Ratcliffe). Even with all the great discoveries his lab has had, Ratcliffe claims that most of lab work is not discoveries, but "management of total failure to understand anything at all" (Peter J. Ratcliffe 2016).

He has received many accolades, becoming a Fellow of both the Royal Society and the Academy of Medical Sciences in 2002, a European Molecular Biology Organization Fellow in 2006, and an honorary member of the American Academy of Arts and Sciences in 2007 (The Canada Gairdner Foundation). He was knighted for services to clinical medicine in 2014 (Magdalen College). Some of his awards, in addition to those shared with Kaelin and Semenza mentioned above, include the Milne-Muerke Foundation Award (1991), Graham Bull Prize (1998), International Society for Blood Purification Award (2002), Louis Jeantet Prize for Medicine (2009), Wellcome Investigator Award in Science (2014), and the Royal Society Buchanan Medal (2017) (The Canada Gairdner Foundation; The Royal Society ; Wellcome).

Sir Ratcliffe married Fiona Mary MacDougall in 1983 and they have two daughters and two sons ("Ratcliffe, Sir Peter (John)" 2018).

\section{Bibliometrics}

The WoS beta Author Search for Sir Peter J. Ratcliffe found 408 publications, resulting in an $\mathrm{H}-$ index of ninety-eight, and a citation count of 48,479 in 25,725 unique articles. The detailed data is drawn off 400 publications, but did not affect his H-index. These 400 publications have been cited 48,265 times (46,442 without self-citations) from 25,580 unique articles (25,314 without selfcitations), averaging almost 121 citations per publication.

Ratcliffe has published at least three articles a year since 1983. By the 1990's he was averaging ten articles a year and there are two years where he published over twenty articles; twenty-five in 
2011 and twenty-two in 2002. (See Figure 3.) Similarly to Kaelin, Ratcliffe's article have been cited every year since 1984. 1984 saw four citations, but that number grew to one-hundred by 1992, one-thousand by 2001, and over two-thousand by 2004 . There have already been eight citations attributed to 2020 (by pre-published articles). (See Figure 4.)

Figure 3. Sir Peter J. Ratcliffe, number of published items in each year. Data source: Web of Science. Retrieved 15 November 2019.

Figure 4. Sir Peter J. Ratcliffe, number of times cited in each year. Data source: Web of Science. Retrieved 15 November 2019.

All of Ratcliffe's top five cited articles are on HIF, and two of them are one the HIF-VHL relationship. (See Table 3.) His most highly cited article "Targeting of HIF-alpha to the von Hippel-Lindau ubiquitylation complex by O-2-regulated prolyl hydroxylation," is the article that was published in the same issue of Science in 2001 as Kaelin's most highly cited article. The Journals that Ratcliffe publishes in are top journals including Blood and the Journal of Biological Chemistry, which is his most published in journal with twenty-four articles. (See Table 4.)

Table 3. Top five most highly cited papers by Sir Peter J. Ratcliffe. Data source: Web of Science. Retrieved 15 November 2019.

Table 4. Top five journals published in by Sir Peter J. Ratcliffe. Data source: Web of Science. Retrieved 15 November 2019.

\section{Gregg L. Semenza}

\section{Life, education, and career}

Gregg L. Semenza was born in 1956 in Flushing, New York to a psychotherapist and an elementary school teacher (Ahmed 2010). He grew up with four younger siblings slightly north of Flushing in North Tarrytown and attended Sleepy Hollow High School where he was first inspired to study biology by his biology teacher Rose Nelson. Nelson inspired Semenza by presenting material as 
discoveries and not a series of dry facts. Having a $\mathrm{PhD}$, she understood what research was and passed on that knowledge and excitement to her students (Begun 2019). Another inspiration for Semenza during this time was the time he spent at a National Science Foundation summer research program, the Boyce Thompson Institute for Plant Research in Yonkers, NY (Ahmed 2010). After graduating fourth in his class in 1974, Semenza went on to earn his B.A. in biology from Harvard University in 1978 (Johns Hopkins Medicine ; Begun 2019). He had initially planned on working in basic genetic research, but a family friend having a child with Down Syndrome combined with him working in a Boston's Children's Hospital genetics lab that was working chromosome 21, drove him to consider becoming a physician and he applied for the $\mathrm{MD} / \mathrm{PhD}$ program at the University of Pennsylvania School of Medicine (Ahmed 2010; Begun 2019). His doctoral research at the University of Pennsylvania was on $\beta$-thalassemia with Elias Schwartz and Saul Surrey at the Children's Hospital of Philadelphia. He earned his MD/PhD in 1984 (Ahmed 2010; Nobelprize.org 2019a).

While working in the Swartch/Surry lab, Semenza decided that specializing in pediatrics would be his best way to prepare for a career in medical genetics as many genetic diseases are apparent at birth and understanding human development is necessary to understand the diseases. He went to Duke University for a pediatrics residency and then did his medical genetics postdoctoral studies at John Hopkins where he established an independent research group (Ahmed 2010; Nobelprize.org 2019a). He is still at Johns Hopkins, becoming faculty in 1990, a full professor in 1999, and Director of the Vascular Research Program at the Johns Hopkins Institute for Cell Engineering in 2003 (Johns Hopkins Medicine ; Nobelprize.org 2019a). He is currently a professor of pediatrics, radiation oncology and molecular radiation sciences, biological chemistry, medicine, and oncology at the Johns Hopkins University School of Medicine and is the C. Michael Armstrong Professor of Pediatrics (Johns Hopkins Medicine).

During his interview with Adam Smith from nobelprize.org, Semenza noted that what he loves about science is how exciting the "unexpected turns" make things and how one never knows where their studies will lead them. It was an unexpected turn that led him to start working on EPO by chance. He had requested a genetic clone of factor VIII, which he wanted to study in mice, from another laboratory. The lab sent him the factor VIII, but also sent him a cloned EPO gene because 
they thought he would find it interesting to study. He did find it interesting, was successful in getting mice to express the human EPO, and continued to study the hormone that eventually led to his fundamental discovery (Ahmed 2010). His current research focuses on the molecular mechanisms of oxygen homeostasis, exploring HIF-1's role in cancer, cerebral and myocardial ischemia, chronic lung disease, and diabetes. Cancer and heart disease are particular areas of interest with recent preclinical work on HIF-1 affecting tumors, gene and stem cell therapy for ischemic cardiovascular disease, and how to protect against ischemia-reperfusion heart injury (Johns Hopkins Medicine).

As with most Nobel Laureates, Semenza already had numerous awards and distinctions. He is editor-in-chief of the Journal of Molecular Medicine, on the editorial board of Molecular and Cellular Biology and Cancer Research, a founding fellow of the American College of Medical Genetics, a member of the Alpha Omega Alpha Honor Medical Society since 1981, the Society for Pediatric Research since 1991 and the American Society for Clinical Investigation since 1995, and was elected to both the Association of American Physicians and the National Academy of Sciences in 2008 and to the Institute of Medicine in 2012. He was also an American Cancer Society Research Professor from 2012-2016. In addition to the awards shared with Kaelin and Ratcliffe, Semenza's awards include the Markey Trust Lucille P. Markey Scholar Award in Biomedical Science (1989), American Heart Association's Established Investigator Award (1994), Children's Brain Tumor Foundation's Jean and Nicholas Leone Award (1999), Society for Pediatric Research's E. Mead Johnson Award for Research in Pediatrics (2000), and the American Society for Clinical Investigation's Stanley J. Korsmeyer Award (2012) (Johns Hopkins Medicine). As for the Nobel, Semenza and Kaelin are the 28th and 29th people affiliated with Johns Hopkins to win the award and Semenza is now one of four Nobel laureates on the university's current faculty ("Johns Hopkins researcher Gregg Semenza wins 2019 Nobel Prize in Physiology or Medicine" 2019).

Early on at John Hopkins, Semenza met Laura Kasch, who runs a genotyping core facility at the university. They married and have three children (Ahmed 2010; "Johns Hopkins researcher Gregg Semenza wins 2019 Nobel Prize in Physiology or Medicine" 2019). 


\section{Bibliometrics}

Gregg L. Semenza's WoS beta Author Search found 519 publications, an H-index of 144, and a citation count of 89,400 in 43,901 unique articles. The data used for more details loses six articles, but does not affect his H-index. These 513 publications have been cited 89,386 times $(85,299$ without self-citations) from 43,888 unique articles (43,506 without self-citations), averaging over 174 citations per publication.

Semenza had two publications in 1984, none in 1985 or 1986, and then at least one publication every year since 1987. He has twelve years with over twenty publications, with thirty in 2013 and thirty-four in 2011. (See Figure 5.) These articles have resulted in at least three citations a year since 1984, except for 1986, which had zero citations. By 1988, every year saw at least ten citations, growing to over one-hundred by 1993, two-thousand by 2002, and over five-thousand by 2012, with 2014-2018 all having over six-thousand citations. (See Figure 6.)

Figure 5. Gregg L. Semenza, number of published items in each year. Data source: Web of Science. Retrieved 15 November 2019.

Figure 6. Gregg L. Semenza, number of times cited in each year. Data source: Web of Science. Retrieved 15 November 2019.

The citation numbers mentioned here may be slightly misleading as one of Semenza's most highly cited articles is the third edition of "Guidelines for the use and interpretation of assays for monitoring autophagy," which is a 240-page review article that has over two-thousand individuals listed as authors. This article has 2,105 citations as of November 15, 2019, making it his fourth most cited article. When taken out of consideration, all of Semenza's five most cited articles are on HIF. (See Table 5.) The 2003 "Targeting HIF-1 for cancer therapy," published in Nature Reviews Cancer, is his most cited article with 4,109 citations, with an average of almost 242 citations a year since publication. The Proceedings of the National Academy of Sciences of the United States of America is the journal Semenza published in the most, having published fortythree articles in the journal. He has published over twenty articles in three other journals, and 
nineteen in his fifth most published in journal. All of these journals are well-respected journals. (See Table 6.)

Table 5. Top five most highly cited papers by Gregg L. Semenza. Data source: Web of Science. Retrieved 15 November 2019.

Table 6. Top five journals published in by Gregg L. Semenza. Data source: Web of Science. Retrieved 15 November 2019.

\section{Conclusion}

On October 7, 2019, three physician-scientists were awarded the Nobel Prize in Physiology or Medicine. The work of these three scientists ended up coming together and building upon each other, resulting in an understanding of the mechanism behind animal cells ability to sense and react to varying levels of oxygen. The implications of this discovery are far-reaching as oxygen is essential in erythroid, cardiac, vascular, and respiratory systems and plays a vital role in countless diseases (Semenza 2001). The importance of oxygen in health is evident to anyone who tries to hold their breath longer than a few minutes. It is probably more evident to health researchers who are extensively and diversely studying it in clinical trials. A quick search in clinicaltrials.gov on November 19, 2019 found almost ten-thousand clinical trials that had something to do with oxygen. The discovery of this year's laureates showing the essential role of HIF has led to some of these studies. As of November 19, 2019, there were 209 HIF clinical trials in various stages in clinicaltrials.gov, sixty on VHL, and over a thousand on EPO. It is almost certain that the work of William G. Kaelin Jr., Sir Peter J. Ratcliffe, and Gregg L. Semenza will be the foundation for numerous more studies resulting in therapies for a wide range of human diseases affecting everyone from neonates to the elderly. 


\section{References}

Ahmed, F. 2010. Profile of Gregg L. Semenza. Proceedings of the National Academy of Sciences of the United States of America 107 (33): 14521-3. https://doi.org/10.1073/pnas.1009481107.

Albadari, N., S. S. Deng, and W. Li. 2019. The transcriptional factors HIF-1 and HIF-2 and their novel inhibitors in cancer therapy. Expert Opinion on Drug Discovery 14 (7): 667-682. https://doi.org/10.1080/17460441.2019.1613370.

American Association for Cancer Research. "William G. Kaelin Jr., MD." Accessed November 8, 2019. https://www.aacr.org/Funding/Pages/scientific-advisory-committeedetail.aspx?ItemID=14.

Begun, A. 2019. "Nobel Prize winner shaped by his experience at local high school." River Journal, 2019. Accessed November 13, 2019.

https://riverjournalonline.com/schools/nobel-prize-winner-shaped-by-his-experience-atlocal-high-school/17789/.

Bessho, R., Y. Takiyama, T. Takiyama, H. Kitsunai, Y. Takeda, H. Sakagami, and T. Ota. 2019. Hypoxia-inducible factor-1 alpha is the therapeutic target of the SGLT2 inhibitor for diabetic nephropathy. Scientific Reports 9. https://doi.org/10.1038/s41598-019-51343-1.

Brown, M. 2016. "2016 Basic Award Overview." Lasker Foundation. Accessed November 14, 2019. https://vimeo.com/185333301.

Bunn, H. F., and R. O. Poyton. 1996. Oxygen sensing and molecular adaptation to hypoxia. Physiological reviews 76 (3): 839-885, https://www.physiology.org/doi/abs/10.1152/physrev.1996.76.3.839.

Chen, N., C. Hao, X. Peng, H. Lin, A. Yin, L. Hao, Y. Tao, X. Liang, Z. Liu, C. Xing, J. Chen, L. Luo, L. Zuo, Y. Liao, B. C. Liu, R. Leong, C. Wang, C. Liu, T. Neff, L. Szczech, and K. H. P. Yu. 2019. Roxadustat for anemia in patients with kidney disease not receiving dialysis. New England Journal of Medicine 381 (11): 1001-1010. https://doi.org/10.1056/NEJMoa1813599.

Chi, Y. B., Q. C. Luo, Y. T. Song, F. S. Yang, Y. Wang, M. M. Jin, and D. H. Zhang. 2019. Circular RNA circPIP5K1A promotes non-small cell lung cancer proliferation and metastasis through miR-600/HIF-1 alpha regulation. Journal of Cellular Biochemistry 120 (11): 19019-19030. https://doi.org/10.1002/jcb.29225. 
Cockman, M. E., N. Masson, D. R. Mole, P. Jaakkola, G.-W. Chang, S. C. Clifford, E. R. Maher, C. W. Pugh, P. J. Ratcliffe, and P. H. Maxwell. 2000. Hypoxia inducible factor- $\alpha$ binding and ubiquitylation by the von Hippel-Lindau tumor suppressor protein. Journal of Biological Chemistry 275 (33): 25733-25741, http://www.jbc.org/content/275/33/25733.full.pdf.

Cole, L. A. 2016. "Adenosine Triphosphate Energetics." In Biology of Life, edited by Laurence A. Cole, 65-77. Academic Press.

Dana-Farber Cancer Institute. "William G. Kaelin Jr., MD." Accessed November 8, 2019. https://www.dana-farber.org/find-a-doctor/william-g-kaelin-jr/.

Epstein, A. C., J. M. Gleadle, L. A. McNeill, K. S. Hewitson, J. O'Rourke, D. R. Mole, M. Mukherji, E. Metzen, M. I. Wilson, A. Dhanda, Y.-M. Tian, N. Masson, D. L. Hamilton, P. Jaakkola, R. Barstead, J. Hodgkin, P. H. Maxwell, C. W. Pugh, C. J. Schofield, and P. J. Ratcliffe. 2001. C. elegans EGL-9 and mammalian homologs define a family of dioxygenases that regulate HIF by prolyl hydroxylation. Cell 107 (1): 43-54. https://doi.org/10.1016/s0092-8674(01)00507-4.

Esser, T. U., K. Roshanbinfar, and F. B. Engel. 2019. Promoting vascularization for tissue engineering constructs: current strategies focusing on HIF-regulating scaffolds. Expert Opinion on Biological Therapy 19 (2): 105-118. https://doi.org/10.1080/14712598.2019.1561855.

Fallah, J., and B. I. Rini. 2019. HIF inhibitors: status of current clinical development. Current Oncology Reports 21 (1). https://doi.org/10.1007/s11912-019-0752-z.

Fitzpatrick, S. F. 2019. Immunometabolism and sepsis: a role for HIF? Frontiers in Molecular Biosciences 6. https://doi.org/10.3389/fmolb.2019.00085.

Francis, A. W., Sr., and L. M. Sayre. 2014. Oxygen. https://doi.org/10.1036/1097-8542.480800.

Gilman, N. V. 2018. Analysis for science librarians of the 2017 Nobel Prize in physiology or medicine: the life and work of Jeffrey C. Hall, Michael Rosbash, and Michael W. Young. Science \& Technology Libraries 37 (1): 22-47.

Grady, D. 2015. "Carolyn Kaelin, breast cancer surgeon, patient advocate and patient, dies at 54." The New York Times, 2015. Accessed November 8, 2019. https://www.nytimes.com/2015/08/10/us/carolyn-kaelin-breast-cancer-surgeon-dies-at54.html. 
Groulx, I., M.-E. Bonicalzi, and S. Lee. 2000. Ran-mediated nuclear export of the von HippelLindau tumor suppressor protein occurs independently of its assembly with cullin-2. Journal of Biological Chemistry 275 (12): 8991-9000, http://www.jbc.org/content/275/12/8991.full.pdf.

Hefti, M. H., K.-J. Françoijs, S. C. de Vries, R. Dixon, and J. Vervoort. 2004. The PAS fold. European Journal of Biochemistry 271 (6): 1198-1208. https://doi.org/10.1111/j.14321033.2004.04023.x.

Hoffman, M. A., M. Ohh, H. F. Yang, J. M. Klco, M. Ivan, and W. G. Kaelin, Jr. 2001. von Hippel-Lindau protein mutants linked to type $2 \mathrm{C}$ VHL disease preserve the ability to downregulate HIF. Human Molecular Genetics 10 (10): 1019-1027. https://doi.org/10.1093/hmg/10.10.1019.

Hong, M., H. L. Shi, N. Wang, H. Y. Tan, Q. Wang, and Y. Feng. 2019. Dual effects of Chinese herbal medicines on angiogenesis in cancer and ischemic stroke treatments: role of HIF-1 network. Frontiers in Pharmacology 10. https://doi.org/10.3389/fphar.2019.00696.

Huang, H., Y. Q. Fan, Z. Gao, W. Wang, N. Shao, L. Zhang, Y. J. Yang, W. F. Zhu, Z. W. Chen, J. J. Hu, and G. H. Ding. 2019. HIF-1 alpha contributes to Ang II-induced inflammatory cytokine production in podocytes. BMC Pharmacology \& Toxicology 20 (1). https://doi.org/10.1186/s40360-019-0340-8.

Huang, L. E., Z. Arany, D. M. Livingston, and H. F. Bunn. 1996. Activation of hypoxiainducible transcription factor depends primarily upon redox-sensitive stabilization of its $\alpha$ subunit. Journal of Biological Chemistry 271 (50): 32253-32259. https://doi.org/10.1074/jbc.271.50.32253.

Huang, L. E., J. Gu, M. Schau, and H. F. Bunn. 1998. Regulation of hypoxia-inducible factor $1 \alpha$ is mediated by an O2-dependent degradation domain via the ubiquitin-proteasome pathway. Proceedings of the National Academy of Sciences of the United States of America 95 (14): 7987. https://doi.org/10.1073/pnas.95.14.7987.

Iliopoulos, O., A. P. Levy, C. Jiang, W. G. Kaelin, Jr, and M. A. Goldberg. 1996. Negative regulation of hypoxia-inducible genes by the von Hippel Lindau protein. Proceedings of the National Academy of Sciences of the United States of America 93 (20): 10595-10599. https://doi.org/10.1073/pnas.93.20.10595. 
Ivan, M., and W. G. Kaelin, Jr. 2001. The von Hippel-Lindau tumor suppressor protein. Current Opinion in Genetics \& Development 11 (1): 27-34. https://doi.org/10.1016/s0959437x(00)00152-0.

Ivan, M., K. Kondo, H. Yang, W. Kim, J. Valiando, M. Ohh, A. Salic, J. M. Asara, W. S. Lane, and W. G. Kaelin, Jr. 2001. HIF $\alpha$ targeted for VHL-mediated destruction by proline hydroxylation: implications for O2 sensing. Science 292 (5516): 464-468, https://sciencesciencemag-org.proxy.binghamton.edu/content/sci/292/5516/464.full.pdf.

Jaakkola, P., D. R. Mole, Y.-M. Tian, M. I. Wilson, J. Gielbert, S. J. Gaskell, A. von Kriegsheim, H. F. Hebestreit, M. Mukherji, C. J. Schofield, P. H. Maxwell, C. W. Pugh, and P. J. Ratcliffe. 2001. Targeting of HIF- $\alpha$ to the von Hippel-Lindau ubiquitylation complex by O2-regulated prolyl hydroxylation. Science 292 (5516): 468-472, https://sciencesciencemag-org.proxy.binghamton.edu/content/sci/292/5516/468.full.pdf.

Jelkmann, W. 2007. Erythropoietin after a century of research: younger than ever. European Journal of Haematology 78 (3): 183-205. https://doi.org/10.1111/j.16000609.2007.00818.x.

Johns Hopkins Medicine. "Gregg L. Semenza, M.D., Ph.D.". Accessed November 14, 2019. https://www.hopkinsmedicine.org/profiles/results/directory/profile/0800056/greggsemenza.

"Johns Hopkins researcher Gregg Semenza wins 2019 Nobel Prize in Physiology or Medicine." 2019. Hub, October 7, 2019. Accessed October 7, 2019 Accessed. https://hub.jhu.edu/2019/10/07/gregg-semenza-nobel-prize-physiology-medicine/.

Johnson, R. 2019 "Interview about the awarded work." Interview by Lotta Fredholm. Nobel Media AB, October 7, 2019. Video, https://www.nobelprize.org/prizes/medicine/2019/prize-announcement/.

Kaelin, W. G., Jr. 2002. How oxygen makes its presence felt. Genes \& Development 16 (12): 1441-1445. https://doi.org/10.1101/gad.1003602.

---. 2016. "Acceptance remarks, 2016 Lasker Awards ceremony." Lasker Foundation. http://www.laskerfoundation.org/awards/show/oxygen-sensing-essential-processsurvival/.

---. 2017. Publish houses of brick, not mansions of straw. Nature 545 (7655): 387-387. https://doi.org/10.1038/545387a. 
---. 2019 "Telephone Interview with William G. Kaelin Jr." Interview by Adam Smith. Nobel Media AB, Phone, https://www.nobelprize.org/prizes/medicine/2019/kaelin/facts/.

Keck School of Medicine. "Past Laureates: Massry Prize Winners (1996 - Present)." University of Southern California. Accessed November 8, 2019. https://keck.usc.edu/massryprize/past-laureates.

Laviv, Y., J. L. Wang, M. P. Anderson, and E. M. Kasper. 2019. Accelerated growth of hemangioblastoma in pregnancy: the role of proangiogenic factors and upregulation of hypoxia-inducible factor (HIF) in a non-oxygen-dependent pathway. Neurosurgical Review 42 (2): 209-226. https://doi.org/10.1007/s10143-017-0910-4.

Ledford, H., and E. Callaway. 2019. Biologists who decoded how cells sense oxygen win medicine Nobel. Nature 674: 161-162. https://doi.org/10.1038/d41586-019-02963-0.

Lee, S., M. Neumann, R. Stearman, R. Stauber, A. Pause, G. N. Pavlakis, and R. D. Klausner. 1999. Transcription-dependent nuclear-cytoplasmic trafficking is required for the function of the von Hippel-Lindau tumor suppressor protein. Molecular and cellular biology 19 (2): 1486-1497, https:/www.ncbi.nlm.nih.gov/pmc/articles/PMC116077/pdf/mb001486.pdf.

Lilly. "William G. Kaelin Jr., M.D." Accessed November 8, 2019. https://www.lilly.com/william-g-kaelin-jr-md.

Lin, C. J., Y. M. Lan, M. Q. Ou, L. Q. Ji, and S. D. Lin. 2019. Expression of miR-217 and HIF-1 alpha/VEGF pathway in patients with diabetic foot ulcer and its effect on angiogenesis of diabetic foot ulcer rats. Journal of Endocrinological Investigation 42 (11): 1307-1317. https://doi.org/10.1007/s40618-019-01053-2.

Lopez-Cano, C., L. P. Gutierrez-Carrasquilla, E. Sanchez, A. Campos, M. Hernandez, S. Fernandez-Veledo, J. Vendrell, and A. Lecube. 2019. "Effect of type 2 diabetes on the expression of hypoxia-inducible factor 1-alpha (HIF-1 alpha): is there a relationship with the clock genes?" 55th Annual Meeting of the European Association for the Study of Diabetes Barcelona, Spain, September 16-20, 2019.

Magdalen College. "Professor Sir Peter Ratcliffe." Accessed November 12, 2019. https://www.magd.ox.ac.uk/member-of-staff/peter-ratcliffe/.

Marquard, B. 2015. "Dr. Carolyn Kaelin, 54; inspiration as surgeon, patient." The Boston Globe, 2015. Accessed November 8, 2019. 
https://www.bostonglobe.com/metro/2015/08/02/carolyn-kaelin-after-her-diagnosis-topbreast-cancer-surgeon-infused-her-work-with-patientperspective/jZHeBy6wN646308z1481UO/story.html.

Maxwell, P. H., M. S. Wiesener, G.-W. Chang, S. C. Clifford, E. C. Vaux, M. E. Cockman, C. C. Wykoff, C. W. Pugh, E. R. Maher, and P. J. Ratcliffe. 1999. The tumour suppressor protein VHL targets hypoxia-inducible factors for oxygen-dependent proteolysis. Nature 399 (6733): 271, https://www.nature.com/articles/20459.pdf.

Morris, N. L., and S. M. Yeligar. 2018. Role of HIF-1 in alcohol-mediated multiple organ dysfunction. Biomolecules 8 (4). https://doi.org/10.3390/biom8040170.

National Center for Health Statistics. 2017. "Deaths and Mortality." Deaths. Centeres for Disease Cntrol and Prevention. Accessed November 5, 2019. https://www.cdc.gov/nchs/fastats/leading-causes-of-death.htm.

Nobelprize.org. 2019a. "Announcement of the 2019 Nobel Prize in Physiology or Medicine." Nobel Media AB 2019. https://www.nobelprize.org/prizes/medicine/2019/prizeannouncement/.

---, October 7, 2019, 2019b, "Press release: the Nobel Prize in Physiology or Medicine 2019," https://www.nobelprize.org/prizes/medicine/2019/press-release/.

---. n.d.-a. "The Nobel Prize in Physiology or Medicine 1922." Nobel Media AB 2019. Accessed October 21, 2019. https://www.nobelprize.org/prizes/medicine/1922/summary/.

---. n.d.-b. "The Nobel Prize in Physiology or Medicine 1931." Nobel Media AB 2019. Accessed October 21, 2019. https://www.nobelprize.org/prizes/medicine/1931/summary/.

---. n.d.-c. "The Nobel Prize in Physiology or Medicine 1938." Nobel Media AB 2019. Accessed October 21, 2019. https:/www.nobelprize.org/prizes/medicine/1938/heymans/facts/.

Ratcliffe, P. J. "Peter Ratcliffe." Offices of the Nuffield Professor of Medicine. University of Oxford. Accessed November 12, 2019. https://www.ndm.ox.ac.uk/principalinvestigators/researcher/peter-ratcliffe\#research.

Ratcliffe, P. J. 2016. "Acceptance remarks, 2016 Lasker Awards ceremony." Lasker Foundation. http://www.laskerfoundation.org/awards/show/oxygen-sensing-essential-processsurvival/.

---. 2019 "Telephone Interview with Sir Peter J. Ratcliffe." Interview by Adam Smith. Nobel Media AB, Phone, https://www.nobelprize.org/prizes/medicine/2019/ratcliffe/interview/. 
"Ratcliffe, Sir Peter (John)." 2018. In Who's Who 2019, 2023. A \& C Black.

Semenza, G. L. 2000. HIF-1 and human disease: one highly involved factor. Genes \& development 14 (16): 1983-1991, http://genesdev.cshlp.org/content/14/16/1983.full.pdf.

Semenza, G. L. 2001. HIF-1, O2, and the 3 PHDs: how animal cells signal hypoxia to the nucleus. Cell 107 (1): 1-3. https://doi.org/10.1016/S0092-8674(01)00518-9.

---. 2016. "Acceptance remarks, 2016 Lasker Awards ceremony." Lasker Foundation. http://www.laskerfoundation.org/awards/show/oxygen-sensing-essential-processsurvival/.

---. 2019 "Telephone Interview with Gregg L. Semenza." Interview by Adam Smith. Nobel Media AB, Phone, https://www.nobelprize.org/prizes/medicine/2019/semenza/interview/.

Semenza, G. L., M. K. Nejfelt, S. M. Chi, and S. E. Antonarakis. 1991. Hypoxia-inducible nuclear factors bind to an enhancer element located 3' to the human erythropoietin gene. Proceedings of the National Academy of Sciences of the United States of America 88 (13): 5680-5684. https://doi.org/10.1073/pnas.88.13.5680.

Semenza, G. L., and G. L. Wang. 1992. A nuclear factor induced by hypoxia via de novo protein synthesis binds to the human erythropoietin gene enhancer at a site required for transcriptional activation. Mol Cell Biol 12 (12): 5447-54. https://doi.org/10.1128/mcb.12.12.5447.

The Canada Gairdner Foundation. "Peter J. Ratcliffe: Canada Gairdner International Award 2010." Accessed November 12, 2019. https://gairdner.org/award_winners/peter-jratcliffe/.

The Francis Crick Institute. "Peter Ratcliffe." Accessed November 8, 2019. https://www.crick.ac.uk/research/find-a-researcher/peter-ratcliffe.

The Royal Society. "Buchanan Medal: Buchanan medalist 2019." Accessed November 12, 2019. https://royalsociety.org/grants-schemes-awards/awards/buchanan-medal/.

University of Oxford. 2019. "Sir Peter J Ratcliffe wins the Nobel Prize in Medicine 2019." University of Oxford News \& Events. Accessed November 12, 2019. http://www.ox.ac.uk/news/2019-10-07-sir-peter-j-ratcliffe-wins-nobel-prize-medicine$\underline{2019}$.

Vanderbilt University Medical Center Office of Research. "William G. Kaelin, Jr., M.D." Accessed November 8, 2019. https://www.vumc.org/oor/person/william-g-kaelin-jr-md. 
Wang, G. L., B.-H. Jiang, E. A. Rue, and G. L. Semenza. 1995. Hypoxia-inducible factor 1 is a basic-helix-loop-helix-PAS heterodimer regulated by cellular $\mathrm{O} 2$ tension. Proceedings of the National Academy of Sciences of the United States of America 92 (12): 5510-5514, https://www.pnas.org/content/pnas/92/12/5510.full.pdf.

Wellcome. "Defining the physiology and therapeutic potential of oxygenases as signalling enzymes." Accessed November 12, 2019. https://wellcome.ac.uk/funding/people-andprojects/grants-awarded/defining-physiology-therapeutic-potential-oxygenases.

Wiley, 2014, "The 13th Annual Wiley Prize in Biomedical Sciences Awarded for Advancements in Oxygen Sensing Systems," https://www.wiley.com/WileyCDA/PressRelease/pressReleaseId-110266.html.

"William G. Kaelin." 2011. Fairfield Citizen, 2011. Accessed November 8, 2019. https://www.fairfieldcitizenonline.com/news/article/William-G-Kaelin-2151090.php.

Xu, K., Y. P. Zhan, Z. T. Yuan, Y. Y. Qiu, H. J. Wang, G. H. Fan, J. Wang, W. Li, Y. J. Cao, X. Shen, J. Zhang, X. Liang, and P. H. Yin. 2019. Hypoxia induces drug resistance in colorectal cancer through the HIF-1 alpha/miR-338-5p/IL-6 feedback loop. Molecular Therapy 27 (10): 1810-1824. https://doi.org/10.1016/j.ymthe.2019.05.017. 